\title{
Is Democratic Learning Possible in a High-Stakes Classroom?
}

\author{
Diana L. Satterfield ${ }^{1}$ \\ ${ }^{1}$ Hammondsport High School, University of Rochester, United States \\ Correspondence: Diana L. Satterfield, Doctor of Education, Hammondsport High School, University of \\ Rochester, United States. E-mail: satterfielddiana@yahoo.com
}

Received: September 25, 2019 Accepted: October 20, 2019 Online Published: October 26, 2019

doi:10.5539/jel.v8n6p83

URL: https://doi.org/10.5539/jel.v8n6p83

\begin{abstract}
However well-intentioned, standardization and increased testing conflict with theories and research that supports authentic learning and collaboration. Implementing methods to empower and engage students can feel nearly impossible within a high-stake environment. This article discusses the findings of an action research study conducted to explore ways for teachers to engage students to become active participants in both teaching and learning. Students were encouraged to explore a democratic learning environment in which they worked collaboratively to develop lesson plans for social studies that adhered to state requirements. The findings showed a profound shift in perceptions of teaching and learning by students and teacher.
\end{abstract}

Keywords: high stakes, democratic learning, student engagement, collaboration, Common Core, authentic learning, student perspective

\section{Introduction}

\subsection{Statement of the Problem and Goals of the Study}

Teachers are creative by nature. However, teaching a high stakes course structured by rigid curricular standards that culminates in a difficult state exam, can make a teacher feel robotic and anything but creative. This situation compelled me to conduct an action research study in a $10^{\text {th }}$ grade Global Studies class to explore the idea of implementing a democratic learning environment. While planning and theorizing the idea with my colleagues had been thrilling, the implementation was terrifying. In order to achieve a democratic learning environment, I planned to actively involve students in both teaching and learning processes. This would occur by teaching students to collaboratively develop their own lesson plans. Although fearful that without traditional instruction the students might not be successful, my colleagues encouraged me to continue. As a result, the findings of this study fundamentally changed the ways I view teaching, learning, and the roles of students and teachers. I hope these findings will prompt a dialogue that challenges traditional methods and roles within the classroom to encourage the promotion democratic learning practices.

\subsection{Brief Background}

Educational research indicates that high stakes testing is counterintuitive to a positive learning and teaching process for both students and teachers (Gee, 2000; Hursh, 2008). Conversely, educational policies at both state and federal levels have increased emphasis on testing of a high stakes nature. The results of these tests are gathered into data used to evaluate students, teachers, and district performance. This topic is germane to current trends in education and to me personally. The rigid parameters of social studies curricula and testing have permitted me to mostly teach of democratic methods, but not to practice them in the classroom.

Throughout my teaching career of twenty years, I have taught exclusively in New York State and hold certifications in Social Studies 7-12 and Special Education K-12. The majority of my experience has been teaching Global Studies and Geography. At the end of the course, students must successfully pass the class and a comprehensive exam a requirement for graduation. Students are given three hours to take the exam and it often takes the entire three hours. Moreover, the passing rates are generally included into teacher evaluations in some manner.

Therefore, high stakes exams and adherence to standards are a national reality. In this study, collaborative lesson planning was introduced as a means to promote democratic learning. Although students designed the plans and chose the assessments, delivered content and scored all assignments. This method encouraged a redefining of 
traditional roles within this social studies classroom. As trust was built amongst the participants, elements of a democratic learning environment emerged. These elements will be presented and discussed in this article.

\subsection{Relevant Scholarship and Theoretical Framework}

Collaborative learning practices are rooted in the social constructivist learning theories of Lev Vygotsky (Drucker, 1999; Moran \& John-Steiner, 2003). Social constructivists view the incorporation of collaborative practices in the educative process as necessary to facilitate learning for students, as well as important to the planning processes for teachers (Fulton, 2003). Vygotsky (1978) proposed that individuals acquire knowledge through social interactions and that, "knowledge construction [is] a social, cooperative venture" (Moran \& John-Steiner, 2003). Therefore, an underlying assumption about collaboration is that learning and knowledge are co-constructed with others. The process of co-construction impacts self-efficacy and promotes positive learning experiences for both the instructor and the learner (Hamilton-Jones \& Vail, 2014). For example, in a writing course taught at an Australian University, students were taught a variety of techniques and then implemented these techniques as they co-wrote a tourism guide with the professor (Humphrey \& McNaught, 2011). Feedback demonstrated that such activities offered insights into scaffolded learning and collaboration as students struggled within the role of the teacher. While extensive research has been conducted regarding the effects of collaboration in education and how it results in more meaningful learning experiences (Jonassen, 1999; Friend \& Cook, 2003), most of this research has focused on professional collaboration and student peer group activities (Broughton \& Putney, 2011; Prideaux, 2009). Far less has been directed toward student-teacher collaborative efforts, and even less has been focused at the high school level or in courses that are considered high-stakes. Therefore, this study explored how student-teacher collaboration could actively engage students in the learning process.

\subsection{Overview and Design}

This study was conducted in a public school, with a tenth grade class, in a rural community in upstate New York. The school is a K-12 facility and the majority of the students live rurally. More than fifty percent of the student body is determined to be in some level of poverty. Hence, the district receives Title I funds. The study was conducted with one section of 14 students, ages 15 to 16, with widely varying abilities. The group included some honor roll students, four students with Individualized Education Plans (IEPs) and two students who were second language learners (SLL). The wide variety of abilities represented in the class is typical of public school. While I was initially concerned with the challenges of these diverse learners, I felt that it would provide a more authentic experience that was transferrable.

\section{Methods and Intervention}

Over the course of approximately twelve weeks, this study considered the nature of a classroom in which the teacher and the students in a 10th grade Global Studies class collaborated to create learning activities and develop assessments that met with the NYS curriculum. We also reflected both individually and together in order to identify areas of success and areas of improvement. The study schedule was designed to adhere to the action research cycle to A) plan, B) act, C) observe, and D) reflect. This four-step iterative plan provided the model for the collaborative lesson.

The first step involved planning. Students were introduced to the state requirements of the course. They were also shown sample state exams required for course credit and graduation. Together, we identified goals and discussed lesson plan activities. Students were taught the lesson planning process. They were instructed to take notes in their classes over the next few days to identify how every class, regardless of the subject, followed a similar pattern of review, introduction, delivery of new content, summary, and practice. This insight prompted extensive dialogue. Random, informal conversations would ensue that compared biology class to English class as students identified each element of the lesson plans. They recognized that although the courses were dramatically different in content, the structure of class was essentially the same. This was the first step toward becoming insiders to teaching, not just learning.

In Step Two of the cycle, we worked to develop lesson plans for a unit. This particular unit was the Age of Revolutions: American Revolution, French Revolution, and Latin American Revolutions. At this point, students had a firm grasp of state requirements. One full class period was utilized to teach the students how to plan lessons: review, introduction, content delivery, practice, reinforcement, timing, etc. Next, we discussed their observations drawn from Step One. Then they brainstormed effective learning activities and created a master list of those activities. I kept field notes while observing their interactions. I noted that the students shared their personal preferences of learning activities, such as note-taking, interactive films, or crosswords. The class was then divided into four groups, with 3-4 members in each. Three of the groups were given the task of designing lesson plans for a particular segment of the unit and one group was assigned to develop assessments. 
In Step Three, students completed a brief survey regarding the experience. The surveys consisted of ten or fewer questions and the results were compiled by an online service. The questions were designed to prompt their ideas about teaching and learning and how their perspectives might change if they become more actively involved in the process. This provided quantitative data were used to design reflective prompts to probe their perceptions in more depth. Using the responses from the reflections, a protocol was developed for focus groups that allowed member checking of my perceptions. This phase of data collection also provided us with an opportunity to discuss what we might change in the next collaboration and aided my own reflections.

Following the first full cycle, we made some changes and began the next phase. The second collaboratively planned unit covered the Industrial Revolution in Britain, Imperialism, and geography. The student-planned lessons became far more creative than I had expected (discussed in the Findings). When the planning and implementation of two units of study were concluded, we again completed a survey and written reflection. This reflection included prompts that guided the student to explore her or his personal experience and views regarding the educational process and their own perspectives of teaching and learning. This was followed by another focus group, two groups of seven people.

\subsection{Analysis: Grounded Theory and Action Research}

Analysis of the data was conducted simultaneously with the collection of the data. Conducting analysis throughout the collection allows the researcher to identify gaps in the data at early stages (Charmaz, 2006). All sources of data i.e., surveys, reflections, transcripts of focus groups, and teacher memos and field notes, were analyzed using a four-step method. This method included two phases of coding that led to the development of categories and then themes (Saldaña, 2009).

As both a participant and researcher, I analyzed the collected data to identify patterns, routines and consistencies. This grounded theory approach, and my participatory role, provided insight to the student perspective. A presupposition of this approach is that data exists in all environments and meaning and theories can be extracted from them (Charmaz, 2006; Emerson, Shaw, \& Fretz, 1995). Moreover, grounded theorists use and emphasize participatory interactions and their co-construction of meaning as primary sources of data and analysis.

The success of this study was due in part to the flexibility of all participants, as well as the willingness to trust one another with to mutually share responsibilities. Experiencing learning and teaching from new perspectives resulted in a democratic learning environment and overall positive experience for the participants.

\section{Results}

As students planned their lessons, each participant utilized activities that were best suited to their own needs. Students became very aware of one another's preferences, including my own. I noted that students were keen to design lessons that met the preferences of their classmates. We all made contributions. Thus, began the collaborative process, and my movement from a dominant role to that of a participant.

\subsection{Evolution of the Democratic Classroom}

Although I sought to observe the dynamics of the collaborative classroom community as one of the guiding research questions, I did not anticipate that it would take on its own energy and identity. Therefore, I labeled it the nature of the collaborative classroom. The term nature is used with purpose, because the environment in the classroom evolved in ways that could not have been planned or predicted. Our interaction, roles, and communication took new forms. This evolution continued throughout the study. The collaborative process was dramatically different at the beginning, middle, and end of the study. Initially, the students were enthusiastic, albeit apprehensive with the study, but over time students became active agents in their learning, as opposed to passive receivers. Additionally, there was increased motivation and willingness to work beyond expectations in all of the students, most of whom I considered reluctant learners. Moreover, students began to design assessments that were more advanced than I had ever planned for this level. For example, they opted to read a book as an assessment and then write formal letters to the author, as opposed to taking a standard quiz. Eventually, even the most reluctant students sought new opportunities for their learning. In these ways, the collaborative classroom evolved into a democratic learning environment.

\subsubsection{Features of the Democratic Classroom}

Examination of the data helped to identify three key elements that contributed to this transition. The most significant were Executive Management and Being an Insider.

\subsubsection{Executive Management}

Executive Management refers to the ability of students to organize learning and assessments, while balancing the 
demands of other courses and activities. These practices were individual and determined by the students. For example, they explained that they were willing to take on additional assignments, such as reading the autobiography because they did not have assigned books in other classes to read at the time. Furthermore, students explained that planning the lessons and knowing the assignments well in advance helped them to manage time more effectively between all classes. Reflecting upon this, they felt that it resulted in the improvement in their grades. The following feedback is provided to further clarify executive management from the perspectives of the participants:

Satterfield: "Why do you think [grades went up] that happened? And I never expected that to happen."

Student: "Because with us planning it we make sure that we learn it and we know what we are learning" (Focus group One, Participant Group One, Lines 66-69, October 2012).

Student: “I don't know. I think it's because we are more interactive and because we know what's going to happen next. So, we are like, prepared" (Lines 261-262).

Student: "For me, about the effort that increased, it is kind of the same. I said that because in normal daily life I see how teenagers fight what they are supposed to, like I do all the time. Like if I am told to do something, I don't want to do it. But if I make it myself, like we did in this, it gives me more of an effort to want to do something. So, it gives more cooperation with the students" (Focus Group Two, Participant Group One, Lines, 75-79, December 2012).

Another consistent element that supported this democratic learning environment was being an insider.

\subsubsection{Being an Insider}

It became apparent that students felt privy to the practice of lesson planning, an activity that they had only experienced passively. This allowed students to take control and be active in their own learning. One student noted,

"Yeah I kinda felt like us putting these lessons together, you know what is upcoming and 'oh we are learning about this today because we built it"” (Focus Group One, Participant Group Two, Lines, 27-28, October 2012).

It was noticeable that student-control of lesson planning freed them to allocate the demands for their time amongst courses and other responsibilities. Not only were the students more involved, but more of their work was completed on time, and with quality. It was the first time in my entire teaching career that a class had a $100 \%$ homework completion rate for the entire semester. I addressed this with the participants in the second reflection and elicited the following responses:

- Yes, and the lesson plans that we made then are showing us that we know what is next.

- When a teenager like us is told to do something we don't really wanna do it but if we choose it ourselves we're more likely to do it. Plus us teenagers have a clue what our schedules are like and we know what we're able to get done or not.

- Because you know what has to be done ahead of time so you know what you have to complete." (Reflection Two, Question Five, December 2012).

Moreover, when asked to describe the overall experience of the study in one word or a phrase, one student responded "insightful". When I asked him to describe this he responded, "Well, we got to see what teachers have to do to plan the lesson plans" (Focus Group Two, Lines, 168-169, December 2012). Therefore, connectivity, executive management, and being an insider were key elements to the functionality of this democratic learning environment.

\subsection{Observations of the Democratic Learning Environment}

After assessing the data, it was my determination that when students engage in a democratic learning environment they became active agents in their learning. Moreover, the extent of creativity, investment and risk-taking cannot be predicted or bounded.

\subsubsection{Creativity}

Students would often alter an assignment or plan at any given time. This would occur spontaneously as the dialogue amongst the participants had become fluid. They were very comfortable to express a new idea to improve a lesson or express displeasure on a given topic. I did not sense students being hesitant to share thoughts as I had in the beginning. There seemed to be no fear of reprisal. Moreover, I would join in at times and make suggestions about ideas that I had. Then we would tweak these together. This environment promoted a free 
exchange that supported participant thoughts and promoted creativity.

When prompted to explain the development of more creative assignments, one student responded, "I feel as though I was more comfortable, because I was interested in the assignment. We chose to do it, so I think there was a feeling of accomplishment we all wanted" (Reflection Two, Question Seven, December 2012).

Students not only became increasingly comfortable with less traditional assignments, but that they were also more willing to take risks.

\subsubsection{Investment and Risk-Taking}

When asked to explain the increased willingness of the class to engage in more challenging assignments as designed by the students, one participant responded, "we're like making the plans and stuff so it was like if it was pressure it was our own faults we made it" (Focus Group One, Participant Group One, Lines, 212-213, October 2012). Over the twelve weeks, students consistently emphasized that their efforts changed when they were allowed to make their own decisions. As students became more confident with the process of developing and completing assignments, they were more willing to take risks and create non-traditional assignments. Choosing to read an autobiography is an example. Following the completion of the book, I suggested a possible assessment would be discussion questions submitted as a formal document. However, the group preferred to compose formal letters to the author, as they were learning the skill in another class. They also suggested that each letter include specific criteria, such as an introduction of the student to the author and the impact that the story made on them personally and their education. Additionally, they incorporated the principles of my discussion questions as a guide for the content of the letters. The following excerpt validates this shift to risk-taking:

"Student: We were more adventurous.

Satterfield: You became adventurous through the process?

Student: I thought we learned our limitations to begin with so then we pushed through them" (Focus Group Two, Participant Group Two, Lines, 227-233, December 2012).

Considering that a primary goal of this study was to explore how collaborative lesson planning would occur in a high-stakes environment, the emergence of increased creativity and risk-taking took me by surprise. It was exhilarating to hear students say that they became more "adventurous" in their education and they seemed more invested in the course.

\subsection{Impact on the Participants}

In the final focus group, students were asked to summarize this collaborative learning experience in a word or a phrase. The following are some of their comments:

"increased scores on all work; better grades; challenging; enlightening; more cooperative for students; interesting to see how the students actually put more effort in; Insightful; Enjoyable; Inspiring; Worthwhile; Engaging; Alright; How much we have learned" (Focus Group Two, 12/3/12).

While these comments demonstrate the positive nature of the experience for most of the participants, it began with trust within the group. As the levels of trust increased, the participants were empowered to design more creative ways of learning. Likewise, the students were empowered as insiders of their own learning and the regulations of the policies imposed upon them. This insider knowledge developed as they explored their perceptions of teaching and learning. Moreover, this environment contributed to an increased rapport with one another, and a willingness to communicate more openly with me. Even when the study concluded, these characteristics remained amongst this group. Throughout the second semester, they freely offered suggestions regarding deadlines, assistance, and their thoughts on any given assignments. Furthermore, they were much more confident in their knowledge of the curriculum and standards. Additionally, I had a closer relationship with these students than with any of my other five sections of global history. Dewey (1938) spoke of teaching as a dynamic continuum in that the teacher affects the future experiences of students. In many ways, this study has reinforced this concept for me.

\subsection{Impact on My Practice}

While I have presented the development of student empowerment, I too, felt a sense of empowerment when I relinquished dominant control of the class. I realized that the student should be the central factor in learning, not me. This empowered me not only to trust the students, but myself as well. Seeking the student perspective has become a part of my practice. I accept that collaborative ventures are daunting when teaching a high stakes course. While I feel a great deal of pressure to adequately prepare students for an exam that can determine their ability to graduate. However, I have learned that my students feel as much pressure, or more, than I do. As such, 
they worked hard to cover necessary content and were diligent when preparing quality lessons. Allowing the students to control some measure of their learning didn't mean that I was out of control. My knowledge and experience were necessary to ensure the success of this study and student preparation. I realized, what's the worst that can happen? If it's not working, we can stop and fix it.

\subsection{Students Are a Valuable Resource}

The students became proficient and confident in their lesson planning by the second attempt in the first research cycle, roughly three weeks after the beginning of the school year. The lessons they designed at that point were not only more meaningful, but they could produce lessons in a 20 -minute time span that would take me two or more hours. Furthermore, they were more invested in these lessons. Also, the activities provided new ideas for me to use in other classes, and I gained valuable insight regarding their preferences and styles. In these ways, the students became a valuable resource to add to my repertoire of methods. They also served as a support group to deal with the pressures in a high-stakes environment.

\section{Discussion: Implications and Contributions to the Field}

Despite the challenges of the study, I contend that the findings can contribute to the literature for practitioners who work within the confines of high stakes environments and add to the literature regarding collaborative studies.

To begin, there is a gap in the literature. Few studies present examples of collaboration between teachers and secondary students and no studies were found that allowed students to design their own lesson plans. Additionally, I found no existing literature of these interventions in a high-stakes environment. This study might provide tools and methods to teachers who seek to implement authentic and meaningful learning activities. The dynamics of power shifted when I became a participant in the collaboration. This created a space for students to truly be at the center of the learning environment that empowered the students and me. Using the students as a resource to design activities and lessons, not only resulted in more meaningful learning and engagement of all students, it also allowed time to observe classroom interactions and develop a deeper sense of rapport with my students. Moreover, the students designed creative lessons that I would not have considered otherwise. All of these areas have implications for teacher preparation programs as well as potential training and professional development for new and veteran teachers. Seeking to understand learning through the perspectives of one's students can expand a teacher's repertoire of teaching and learning strategies and revitalize her professional life. I encourage teachers, who have become frustrated with the demands standards-based courses and high stakes testing, to consider this approach as a whole or in part.

Despite limitations, the findings from this study contribute to the literature on increasing student participation and authentic learning practices while aligning to mandated standards, in a number of complementary ways.

\subsection{Final Thoughts}

“It feels more like I guess I don't know how to put it. Kinda like a family. It doesn't really feel like we're really like being talked down and we do not have to do every little thing possible. Like school. It's more like we are actually communicating more. Therapy" (Focus Group 1, Lines 261-264).

Making a positive impact on the lives of young people during the transitional teen stage is rewarding and gives purpose to my life. This can be difficult to convey to people who criticize educators. However, when reviewing the transcript of the focus group, the selection above reminded me of the positive impact we have. Her words are powerful because, we did sort of feel like a family.

\section{References}

Amerin-Beardsley, A., Berliner, D. C., \& Rideau, S. (2010). Cheating in the first, second, and third degree: Educators' responses to high-stakes testing. Educational Policy Analysis Archives, 18(14). https://doi.org/10.14507/epaa.v18n14.2010

Belgarde, M. J., Mitchell, R., \& Arquero, A. (2002). What do we have to do to create culturally responsive programs? The challenge of transforming American Indian teacher education. Action in Teacher Education, 24, 42-54. https://doi.org/10.1080/01626620.2002.10734418

Blue-Banning, M., Summers, J. A., Frankland, H., Nelson, L., \& Beegle, G. (2004). Dimensions of family and professional partnerships: constructive guidelines for collaboration. Exceptional Children, 70(2), 167-184. https://doi.org/10.1177/001440290407000203

Bogdan, R. C., \& Biklen, S. (2007). Qualitative research for education: An introduction to theories and methods (5th ed.). Boston: Pearson. 
Charmaz, K. (2006). Constructing grounded theory: A practical guide through qualitative analysis. London: Sage.

Christie, B. (2000). Topic teamwork: A collective integrative model for increasing student-centered learning in grades K-12. The Journal of Physical Education, Recreation \& Dance, 71(8), 28-35. https://doi.org/10.1080/07303084.2000.10605188

Dewey, J. (1938). Experience and education. New York: Macmillian.

Drucker, P. F. (1999). The new pluralism. Leader to Leader, 14, Fall. https://doi.org/10.1002/1t1.40619991405

Emerson, R., Fretz, R., \& Shaw, L. (1995). Writing ethnographic fields notes. Chicago: The University of Chicago Press. https://doi.org/10.7208/chicago/9780226206851.001.0001

Friend, M., \& Cook, L. (2003). The fundamentals of collaboration. Interactions: Collaboration Skills for School Professionals (4th ed.). Boston, MA: Allyn and Bacon.

Fulton, K. P. (2003). Redesigning schools to meet 21st century learning needs. The Journal, 30(9), 30-35. Database online. Available from EBSCOhost Academic Search Premier. Retrieved from http://www.epnet.com/ehost/login. html

Gee, J. P. (2000-2001). Identity as an analytic lens for research in education. Review of Research in Education, 25, 99-125. https://doi.org/10.2307/1167322

Hamilton-Jones, B. M., \& Cynthia, O. V. (2014). Preparing Special Educators for Collaboration in the Classroom: Pre-Service Teachers' Beliefs and Perspectives. International Journal of Special Education, 29(1), 76-86. Eric. https://doi.org/10.1107/S0108270113015370/sk3488sup1.cif

Hursh, D. (2008). High-stakes testing and the decline of teaching and learning. Lanham MD: Rowman and Littlefield.

Johnson, L. J., Pugach, M. C., \& Hawkins, A. (2004). School-Family Collaboration: A Partnership. Focus on Exceptional Children, 36(5), 1-12. https://doi.org/10.17161/fec.v36i5.6803

Kuh, G. D. (1995). The other curriculum: Out-of-class experiences associated with student learning and personal development. Journal of Higher Education, 66(2), 123-155. https://doi.org/10.2307/2943909

Moran, S., \& John-Steiner, V. (2003). Creativity in the making: Vygotsky's contemporary contribution to the dialectic of development and creativity (Ch. 2, Creativity and development. Eds. Keith R. Sawyer, Vera John-Steiner, Seana Moran, Robert J. Sternberg, David H. Feldman, Howard Gardner, Jeanne Nakamura, and Mihaly Csikszentmihalyi). Oxford; New York: Oxford Univ. Press.

Newmann, F. M. (1992). Student engagement and achievement in American secondary schools. Teachers College: Columbia University.

Papert, S. (1993). Rethinking school in the age of the computer. Basic Books: New York.

Papert, S., \& Harel, I. (1991). Situating constructionism. In S. Papert \& I. Harel (Eds.), Constructionism. New York: Ablex.

Peterson, K. (2002). Positive or negative. Journal of Staff Development, 23(3), 10-15.

Prideaux, D. (2009). Integrated learning. In J. A. Dent \& R. M. Harden (Eds.), A practical guide for medical teachers (3rd ed., pp. 181-186). Edinburgh: Churchill Livingstone.

Saldaña, J. (2009). The coding manual for qualitative researchers. London: Sage.

Vygotsky, L. S. (1978). Mind in society: Development of higher psychological processes (Edited by Cole, M., John-Steiner, V., Scribner, S., \& Souberman, E.). Cambridge, MA: Harvard University Press.

Wright, W. E. (2002). The effects of high stakes testing in an inner-city elementary school: The curriculum, the teachers, and the English language learners. Current Issues in Education [On-line], 5(5). Retrieved from http://cie. ed asu.edu/volume5/number5/

\section{Copyrights}

Copyright for this article is retained by the author, with first publication rights granted to the journal.

This is an open-access article distributed under the terms and conditions of the Creative Commons Attribution license (http://creativecommons.org/licenses/by/4.0/). 